\title{
Bolsas de Valores como Espaços Etnográficos: três olhares
}

\author{
Juliane Bazzo \\ Universidade Federal do Rio Grande do Sul (UFRGS), RS, Brasil \\ E-mail: bazzojuliane@gmail.com
}




\section{Resumo}

O ensaio analisa comparativamente três etnografias cujo ponto comum reside no espaço do trabalho de campo: bolsas de valores, hoje entidades centrais na operacionalização de mercados globais. Instituições financeiras de São Paulo, Chicago, Londres e Shanghai sediaram os referidos empreendimentos etnográficos. A reflexão tecida aqui abraça o pressuposto básico da etnografia como elemento constitutivo da construção do conhecimento antropológico, ou seja, não restrita a uma metodologia. Nesse sentido, o ensaio busca evidenciar como o conteúdo do citado trio de etnografias abre possibilidades de pensar acerca de temáticas, tanto clássicas quanto contemporâneas da disciplina, dentre elas, os rituais de dádiva, a economia global, a religião e as emoções. Em tal esforço, confere-se cuidado em evidenciar aspectos de gênero, já que as etnografias são assinadas por três antropólogas. Ademais, dedica-se atenção às relações Ocidente-Oriente e Norte-Sul, haja vista os trabalhos antropológicos em questão terem se dado em diferentes localidades mundiais.

Palavras-chave: Antropologia. Etnografia. Bolsas de Valores.

\section{Abstract}

The essay analyzes comparatively three ethnographies whose common point lies in the field work space: stock markets, which are central entities in implementing global markets nowadays. Financial institutions in São Paulo, Chicago, London and Shanghai hosted these ethnographic projects. The reflection written here embraces the basic assumption of ethnography as a constitutive element of anthropological knowledge construction, in other words, it is not restricted to a methodology. In this sense, the essay seeks to make evident how the content of that mentioned trio of ethnographies open possibilities for thinking about both classical and contemporary disciplinary themes, among them, the gift rituals, the global economy, religion and emotions. In this effort, care-giving is evident in aspects of gender, as ethnographies are signed by three women. Moreover, some attention is dedicated to East-West and North-South relationship, as shown by the anthropological papers involved have been given in different locations worldwide.

Keywords: Anthropology. Ethnography. Stock Exchanges. 


\section{Introdução}

E dinheiro [...]? Gosta dessa dama? [...] Ela se deita na cama à noite ao seu lado, olha para você, com um olho aberto. Dinheiro é uma megera que nunca dorme. E tem ciúmes. Se não prestar atenção, você acorda de manhã e ela pode ter ido embora para sempre. [...] Então case-se com ele, certo? (Gordon Gekko, protagonista do filme Wall Street)

Dara uma conferência recente, Peirano (2014) lançou mão de um título intrigante: "Etnografia não é método". A partir dessa afirmação, a autora buscou problematizar a empreitada etnográfica, "ideiamãe da antropologia", como algo além de um modo específico de fazer pesquisa, a fim de situá-la como "parte do empreendimento teórico" da disciplina. Nesse sentido, as monografias clássicas persistem como objetos de reflexão não por atuarem como espelhos fiéis de realidades culturais, posto impossível, mas porque se revelam capazes de travar interlocuções densas tanto com o patrimônio "teórico-etnográfico" que as precede, quanto com aquele que as sucede.

Dessa maneira, monografias bem-sucedidas "vulneram nossa própria cosmologia" pela via do exercício comparativo, o qual gera não novas "teorias dos etnógrafos" e sim aportes construídos a partir dos relacionamentos entre eles e os sujeitos de pesquisa em campo. Afirma Peirano (2014, p. 5): “Todo antropólogo está, portanto, constantemente reinventando a antropologia [...] A antropologia é resultado de uma permanente recombinação intelectual". É à luz de tais pressupostos que o presente ensaio propõe-se a discutir três etnografias cujo ponto comum encontra-se no espaço de trabalho de campo: bolsas de valores, hoje instituições centrais na operacionalização do mercado financeiro mundial. 
Por meio da abordagem comparada desse trio de pesquisas, pretende-se aventar as contribuições delas para debates que permeiam atualmente a antropologia da economia, subárea disciplinar a que aparecem conectadas. Mas não apenas isso: há a intenção de verificar subsídios ofertados para outros campos não diretamente vinculados, como a antropologia da religião e das emoções. Embora abrace certa compartimentalização, esta análise o faz unicamente para fins analíticos. Tal opção pauta-se, em verdade, na ideia de O. Velho (2010) de que interfaces entre as distintas vertentes antropológicas demonstram-se cada vez mais fundamentais para apreender "variantes de movimentos cosmopolitas" que povoam a contemporaneidade. As bolsas de valores, sem dúvida, são parte desse cenário.

\section{Três Antropólogas em Campo}

Quando iniciou trabalho de campo na França rural, em fins dos anos de 1960, para desenvolver uma etnografia sobre a feitiçaria, Favret-Saada (2005, p. 157) conta que costumava ouvir dos locais: "Feitiço, quem não pegou não pode falar disso". Essa espécie de afirmação conduziu a pesquisadora a se deixar "afetar" pela feitiçaria na busca por compreendê-la. A experiência dessa estudiosa é trazida à baila porque oferece bom substrato para uma apresentação inicial das três etnografias que estão no centro deste ensaio, todas de autoria de antropólogas.

Como Favret-Saada, essas pesquisadoras também escutaram de seus informantes, mais ou menos abertamente, que para entender o mercado de ações, é preciso vivê-lo. Com isso em mente, o conteúdo do trio de monografias será brevemente exposto considerando em que grau suas autoras se permitiram "afetar" pela dinâmica das bolsas de valores e em que medida isso se revelava possível, dada a condição feminina delas em um universo predominantemente masculino.

Müller (2006) realizou trabalho etnográfico ao longo de 1993 na antiga Bolsa de Valores de São Paulo (Bovespa) ${ }^{1}$. À época, o pregão à viva voz predominava, não obstante, registravam-se as primeiras implicações da coexistência com o mercado eletrônico, que mais tarde se tornaria o meio exclusivo para os negócios. A autora, embora destaque 
repercussões iniciais dessa transição, foca-se em analisar a bolsa como "instituição social exemplar" para clarificar a "dimensão simbólica constituinte" dos relacionamentos mercadológicos que perpassam a sociedade contemporânea.

O levantamento de dados ocorreu por meio de entrevistas e observações. Estas últimas, nas dependências da Bovespa, deram-se a partir de um "aquário" que ladeava o salão de negociações à viva voz. $\mathrm{Na}$ área do pregão, onde a confrontação física era parte inerente do ato de apregoar, apenas homens atuavam naquele momento, muito embora algumas poucas mulheres já tivessem ali trabalhado, visto não haver impedimento institucional de gênero.

No aquário, por sua vez, Müller dialogou com informantes mulheres, representantes de corretoras de valores ou investidoras autônomas. Nesse espaço, à medida que estabeleceu relacionamentos, foi instigada por operadores a ingressar como participante no mercado acionário. Ela não cedeu ao convite mas, em um trecho de seu diário de campo, afirma imaginar o que faria se ganhasse uma boa quantia em dinheiro e, a partir disso, diz ter começado a melhor entender ações e sentimentos dos sujeitos pesquisados.

Zaloom (2006) iniciou sua etnografia na Bolsa de Chicago em fins dos anos de 1990, quando essa instituição vivia um momento polêmico, de passagem do pregão à viva voz para o eletrônico. Essa transformação, abraçada por segmentos administrativos da bolsa, encontrou resistência entre os operadores. Segundo eles, a mudança impactaria negativamente toda uma cultura de negociação construída ao longo do tempo, baseada em relações face a face para comerciar, dentre outros, um tipo específico de produto financeiro, os contratos derivativos, nos quais Chicago tornou-se uma referência para o mundo².

Diante desse cenário, a pesquisadora analisou as repercussões da transição sob o ponto de vista de três atores fundamentais: os designers, responsáveis por mobilizar recursos humanos, materiais e tecnológicos para operacionalizar o mercado; os administradores da bolsa; bem como os investidores que movimentam o dia a dia da instituição. Para tanto, graças à intermediação do filho de um casal que a hospedou em Chicago, um membro do mercado, ela trabalhou em uma corretora 
de valores, no cargo de auxiliar de pregão. No salão de negociações à viva voz, sua função era repassar aos operadores informações de compra e venda transmitidas via telefone por funcionários alocados no escritório da empresa.

Tal posição figurava como a primeira de uma trajetória profissional na bolsa. Implicava manter uma comunicação sem equívocos, em meio à agitação das negociações, aprendizado ao qual a antropóloga se lançou. Esse envolvimento a levou a Londres, onde a organização na qual trabalhava, afinada com a transformação que se dava em Chicago, optou por abrir uma filial voltada ao intercâmbio eletrônico de derivativos.

Na capital inglesa, local em que o mercado já havia sido digitalizado, a pesquisadora integrou um grupo de operadores trainees que receberam capacitação para atuar no universo virtual e, ao mesmo tempo, manter viva uma cultura de negociação típica da cidade estadunidense. Além dessa imersão no dia a dia do segmento financeiro, Zaloom buscou dados complementares em arquivos institucionais, no conteúdo midiático, em entrevistas com profissionais e em eventos do setor.

Por fim, aventurou-se como investidora: mesmo sem capital, aceitou o jogo proposto por um informante, no qual anotaria supostas movimentações mercadológicas diárias. Caso bem-sucedida, ele lhe retribuiria em centavos e vice-versa, como numa aposta. Essa alternativa permitiu à estudiosa ampliar o entendimento daquilo que lhe diziam os operadores: a vivência do risco é intensamente pessoal; constitui algo sentido, que nem sempre pode ser dito. Para o gênero feminino, contudo, a experiência do risco guardava restrições: mulheres atuantes diretamente no pregão em Chicago, uma minoria, eram respeitadas, porém, não veneradas como os grandes investidores homens.

Hertz (1998) desenvolveu atividades etnográficas na Bolsa de Shanghai durante o ano de 1992, quando essa instituição obteve um boom de negócios, em um contexto de abertura econômica da China. Ao contrário de outros pesquisadores estrangeiros, a antropóloga não encontrou obstáculos políticos ao estudo: por se tratar de um momento ímpar na trajetória nacional, as autoridades do país o entendiam 
como oportuno de registro. Hertz buscou assim mapear as complexas interfaces entre uma entidade econômica ocidental e uma sociedade oriental, as quais resultaram, segundo ela, em um arranjo tipicamente chinês e não capitalista, como alardeava a imprensa internacional.

Ao criar a bolsa de valores, o governo chinês objetivava reabastecer os cofres públicos, por meio de uma série de poupanças individuais transformadas em investimentos. Para tanto, conclamou os cidadãos a se tornarem operadores, os quais compraram a ideia e geraram uma verdadeira "febre de ações", mobilização de magnitude histórica comparável à Revolução Cultural. O Estado, por seu turno, não imaginava tamanho envolvimento popular, o qual lhe exigiu astúcia para manter a posição de agente controlador de um mercado em amadurecimento, que se inclinava a uma volatilidade indesejada.

Diante disso, relata a antropóloga, não foi difícil encontrar informantes: pessoas lotavam corretoras todos os dias para realizar operações e, mesmo aqueles que não negociavam, debatiam cotidianamente o assunto. Desse modo, ela pôde conversar com diferentes perfis de investidores em entrevistas, eventos, reuniões e jantares, inclusive com mulheres. Estas, não obstante, compunham uma minoria, dada a hierarquia de gêneros chinesa, que reserva prioritariamente ao homem a atuação na esfera pública. Ademais, não raro a própria antropóloga era convocada a atuar como informante, tendo em vista que os chineses lhe solicitavam dicas ocidentais para ganhar dinheiro na bolsa.

A despeito disso, o acesso de Hertz ao mercado acionário chinês como investidora estava socialmente vetado, pois sob a ótica nativa, a antropóloga norte-americana, radicada na Suíça, já era "rica". Em vão, ela tentou lhes explicar que não possuía sequer um montante financeiro inicial para negociar. Ao mesmo tempo, a pesquisadora relata que, a princípio, exasperava-se com a resposta dos chineses ao questionamento sobre por que haviam ingressado na bolsa. Até mesmo grandes investidores respondiam: "Porque somos pobres".

Reflexões posteriores, entretanto, evidenciaram a Hertz que, do ponto de vista chinês, ela automaticamente detinha "capital social e cultural" por pertencer ao lado ocidental do mundo. Desse modo, a estudiosa concluiu algo fundamental: etnografar espaços mercadoló- 
gicos como as bolsas de valores significa, necessariamente, aprofundar o conhecimento sobre relações de poder, em diversas escalas.

\section{Um Apanhado das Etnografias: diferenciais e contribuições}

Os três referidos trabalhos apresentam forma e conteúdo que podem ser inspiradores ao desenvolvimento de novas etnografias, tanto na área da antropologia econômica, quanto na disciplina como um todo. Esta seção dedica-se a reunir elementos estruturais e analíticos que se destacam no trio de monografias já brevemente descrito.

Müller (2006), cuja etnografia sediou-se na antiga Bovespa, se utiliza das "ordens de grandeza" ou "mundos" delimitados por Boltanski e Thévenot (1991) para demonstrar que a operação cotidiana da bolsa de valores se dá por meio de princípios, códigos e práticas não estritamente provindos de uma ciência econômica, como idealmente se deseja, se acredita e se divulga no senso comum. São relações socioculturais concretas as responsáveis por movimentar de fato essa entidade financeira, onde se configuram uma série de tensões diárias, que necessitam ser equacionadas, de modo a proteger a legitimidade institucional.

Dentre as "ordens de grandeza" arquitetadas por Boltanski e Thévenot (1991), a imagem pública da bolsa de valores se conecta mais diretamente aos "mundos mercantil, industrial e cívico", no sentido de que se atribui a tal instituição o comprometimento com a efetuação de negócios, com a alavancagem da produtividade e com o respeito à legalidade. Não obstante, internamente, tais "ordens de grandeza" mesclam-se nas bolsas de valores a elementos dos chamados "mundos da opinião, doméstico e inspirado" que, respectivamente, dizem respeito à influência e ao prestígio, às relações pessoais e aos "valores transcendentes" dos operadores de mercado.

Longe de situar tais "ordens de grandeza" como uma tipologia estanque, a etnógrafa as emprega para alcançar objetivos analíticos claros: ampliar reflexões para além de uma conceituação econômica que, tradicionalmente, permeia abordagens sobre as bolsas de valores; evitar uma separação artificial entre teorias e práticas de mercado, tendo em vista que ambas se constroem concomitantemente; impedir que 
a etnografia do cotidiano da bolsa de valores a situe simplesmente como uma entidade desviante, tendo em vista que a autora postula como fator constituinte a qualquer instituição a existência de contradições entre ideais e práticas, sendo o desafio antropológico problematizá-las.

Tal estratégia de abordagem alcança seu ápice no capítulo final do estudo, em que a autora evidencia a referida mescla de "ordens de grandeza" por meio da exposição aprofundada da trajetória profissional de três informantes, que ocupam posições bastante diferenciadas no mercado. Esses personagens são chamados, ficticiamente, de Maurício, gerente de um grande banco de investimentos; Gringo, operador autônomo atrelado a especuladores de grande porte; e Sofia, uma "jogadora", jargão pelo qual se denominam especuladores de pequeno porte.

O itinerário de Maurício o vincula prioritariamente aos "mundos mercantil, industrial e cívico": ele trabalha para uma instituição mercadológica publicamente legitimada a operar na bolsa, graças a uma formação acadêmica que o preparou para realizar os mais produtivos investimentos, a partir de fundamentos técnicos. Gringo, por sua vez, também se movimenta pelo "mundo mercantil", na busca pelas melhores operações, porém, sua atuação de ênfase especulativa lhe demanda navegar pelos "mundos doméstico e da opinião", nos quais a influência das relações pessoais permitem trocas informativas impulsionadoras dos negócios.

A trajetória de Gringo detém uma característica fluida que a de Maurício, de ordem conservadora, não possui, haja vista que o operador autônomo trabalha na esfera da especulação, a qual, embora seja necessária para a liquidez das trocas mercadológicas, guarda também um sentido socialmente negativo. Isso se deve à sua conexão com crises financeiras, no âmbito das quais o objetivo idealmente central das bolsas de valores, que seria efetuar a "democratização da propriedade do capital", acaba completamente desvirtuado em prol do lucro de uns poucos, pela via da falência de uma maioria de negociantes.

Sofia, por seu turno, na posição de "jogadora", é representante dos "párias do mercado": pequenos especuladores, cuja atuação se dá estritamente num "mundo inspirado", ou seja, como num jogo de azar, sem auxílio de grande cacife financeiro, de amplas redes de 
relacionamento ou de fundamentos técnicos mais precisos. Os "jogadores" são vistos pelos demais integrantes da bolsa de valores como "viciados no mercado" e criadores fáceis de dívidas, especialmente em momentos de crises.

Obviamente, esses três operadores prototípicos não estão presos de uma vez por todas aos "mundos" mencionados; entretanto, associam-se de maneira mais específica a certas "ordens de grandeza", no interior das quais definem suas práticas de ação, suas identidades pessoais, seu reconhecimento público e os negócios que realizam, os quais impactam, por fim, a movimentação global da bolsa de valores.

Resultado do trabalho de campo que transitou entre os mercados de Chicago e Londres, a etnografia de Zaloom (2006), cujo foco temático reside no fenômeno da dispersão planetária dos pregões eletrônicos, tem um início inusitado: começa pela abordagem da materialidade da "vida financeira", expressa em espaços e em tecnologias. Esse caminho analítico desperta atenção, haja vista que leva a questionar por que a autora coloca ênfase, de saída, em certos componentes de natureza material cuja importância, aparentemente, estaria se perdendo com a virtualização das negociações.

A partir da reconstrução história da constituição da Bolsa de Chicago, narrada sob um olhar antropológico, Zaloom evidencia que dar uma forma material a trocas abstratas colocou-se como uma questão fundamental e permanente nesse processo. Nesse sentido, a devida configuração de espaços físicos, conjugada a eficientes intervenções tecnológicas, foi entendida desde cedo como via para corporificar um modelo teórico de "mercado perfeito", onde poderiam imperar plenamente princípios como a livre concorrência entre os operadores, a racionalidade e agilidade dos negócios, bem como a transparência e confiabilidade institucionais. Por conseguinte, cada inovação material significou uma tentativa de aproximação a ideais mercadológicos, mas também um desafio de adaptação de antigas para novas formas de negociação.

Desse modo, a etnógrafa convida a compreender a tecnologia num sentido amplo, ou seja, não apenas vinculada às recentes descobertas do universo digital, mas como todo e qualquer conjunto estruturado de conhecimentos com poder de intervenção sobre a realidade. Nesse 
sentido, constituem tecnologias as vias de transporte que criaram em Chicago um mercado regional; o telégrafo que transformou a bolsa da cidade em um mercado nacional e a informatização que a elevou a mercado transnacional.

Tais tecnologias não foram alocadas em vazios, mas sim em espaços também tecnicamente manipulados para tanto. Esse conjunto inclui, por exemplo, desde a construção de estradas e ferrovias para o intercâmbio físico de mercadorias negociadas, passa pela arquitetura imponente dos edifícios que abrigaram a bolsa, até o design propriamente dito das salas de negociações, sejam à viva voz ou eletrônicas. O pressuposto unificador de todas essas intervenções é que organização espacial significa melhor circulação de informações e de produtos que, por sua vez, implica maior lucratividade.

Com essa discussão como aporte inicial da etnografia, Zaloom permite um olhar amplificado à sua questão central de reflexão, que é a pulverização mundial dos pregões eletrônicos. Por meio da trajetória emblemática da Bolsa de Chicago, ela demonstra que a mudança tecnológica situa-se como parte integrante à consolidação desse tipo de instituição financeira e que a digitalização não representa uma última e acabada etapa, em meio à busca ideal e incessante pelo "mercado perfeito". Dessa forma, a autora abre um atalho para novas pesquisas, que deem conta de acompanhar o porvir.

Na conclusão da monografia, Zaloom levanta mais uma "questão de geografia" que demanda atenção. Ela afirma que, a despeito das expressivas transformações desencadeadas pela virtualização, as cidades continuam a atuar como polos de referência aos negócios planetários. No panorama mundial do mercado financeiro, algumas cidades, como Nova York, Londres e Tóquio, detêm preponderância e os estilos locais de negociação, a exemplo dos derivativos em Chicago, continuam a existir. Diante disso, a autora rejeita a tese de insignificância das cidades perante as bolsas eletrônicas e defende a necessidade de novas reflexões sobre como a dinâmica das urbes vem influenciando as operações on-line.

Hertz (1998) também lança mão de uma abordagem histórico -antropológica de longo alcance a fim de sustentar sua tese de que a Bolsa de Shanghai, a despeito de ancorar-se num modelo de instituição 
ocidental, constitui um empreendimento singularmente chinês, não apenas econômico, mas político. Explica ela que tal configuração foi possível graças à "extraordinária resiliência", desde os idos imperiais, de duas lógicas diferentes, porém, interdependentes, de organização social no país.

A mais proeminente delas expressa-se em um modo de produção tributário, por meio do qual um agente soberano - na atualidade, o Estado - resgata excedentes produtivos de vários segmentos de trabalhadores por meio da cobrança direta de impostos. A segunda lógica, englobada pela primeira, refere-se a um modo de produção capitalista de pequena escala, no âmbito do qual produtores de classes dominantes extraem excedentes produtivos de classes plebeias, por meio do trabalho assalariado ou via privilégios estabelecidos por um sistema hierárquico e tradicional de parentesco e gênero. Esse pequeno capitalismo nunca evoluiu a um capitalismo propriamente dito pelo fato de subjugar-se a um arranjo maior, que é o tributário, o qual garante, a um só tempo, a hegemonia estatal, bem como a naturalização e estabilidade de um sistema de desigualdades de classes.

A história da China revela que, embora o ingresso de elementos do capitalismo ocidental tenha perpetrado ameaças a tal estado de coisas, acabou efetivamente ofertando novas vias para seu fortalecimento. Um exemplo nesse sentido diz respeito às sucessivas investidas chinesas em alavancar a industrialização do país: tais esforços delimitaram a criação de uma série de empresas, entretanto, sob o controle do Estado, quadro que terminava por reproduzir a ordenação social anteriormente descrita. Nessa mesma direção, portanto, a Bolsa de Shanghai representa outro exemplo simbólico.

Um dos diferenciais da etnografia de Hertz está, sem dúvida, na possibilidade que a antropóloga teve de revisitar o cenário de estudo, tendo em vista que o trabalho de campo ocorreu ao longo de 1992, ano de lançamento da bolsa, mas a publicação em livro aconteceu apenas em 1998. Em um posfácio, ela pôde então relatar as medidas que o governo implementou nesse ínterim com o intuito de retomar o controle do mercado, que vivenciou, a princípio, índices de volatilidade não bem-vindos, em virtude de uma "febre de ações" impulsionada pelos investimentos dos cidadãos chineses. 
Hertz assinala o ingresso maciço das chamadas "organizações" como operadoras de mercado, que são empresas de seguros e investidores institucionais amparados pelo Estado, cujo calibre revelava-se capaz de orientar a maior parte do volume de negociações. Desse modo, sem excluir os demais investidores, o governo restabeleceu o domínio do movimento da bolsa. Em tal estratégia, percebe-se claramente a elasticidade e a resistência da mencionada lógica tributária associada a um pequeno capitalismo: o Estado, como agente soberano, controla o mercado acionário, ao mesmo tempo em que não exclui, mas sim engloba, de maneira subordinada, os operadores independentes.

Dessa forma, aquilo que os analistas econômicos ocidentais apontaram como defeito da Bolsa de Shanghai - a excessiva intervenção estatal - coloca-se, em verdade, como efeito de uma dinâmica histórica e, consequentemente, como marca distintiva do mercado de ações chinês, sendo ele projeto de um sistema político-econômico particular.

\section{O Lugar das Bolsas na Antropologia Econômica}

A consolidação da antropologia econômica como subárea disciplinar ocorreu em meados do século XX, com o debate entre as correntes de pensamento formalista e substantivista. A primeira sustentava-se em modelos generalistas da economia neoclássica. A segunda, em contraposição, alicerçada na filosofia de K. Polanyi, defendia a análise dos eventos econômicos na concretude da vida sociocultural. É a partir dessa bandeira levantada pelos substantivistas que a etnografia emerge como "ferramenta reflexiva para a economia". (Riveros, 2013)

Todavia, nos anos de 1970, a antropologia econômica ingressa em um momento de certo obscurantismo no âmbito das ciências sociais, diante do florescimento da antropologia simbólica, que arrebanhou ícones como M. Sahlins e C. Geertz, anteriormente envolvidos na discussão substantivista. Esse estado de coisas começa a experimentar uma reviravolta no final da década de 1980, com a evolução dos estudos antropológicos acerca do consumo, encabeçados por autores como M. Douglas, A. Appadurai e D. Miller. Não obstante, segundo Riveros (2013), a grande retomada da antropologia econômica acontece em 
consonância com a ocorrência das chamadas crises financeiras globais, notadamente a de 2008.

As interrogações geradas pela dupla face desses fenômenos que poderiam significar tanto o insucesso quanto o êxito capitalista neoliberal - incitaram a comunidade antropológica a uma nova gama de reflexões. Como assinala Ortiz (2014), a pergunta antropológica tornada imprescindível em tal quadro foi a seguinte: “Depressão para quem?". O autor explicita que a crise de 2008 não pode ser compreendida como dispersa planetariamente, visto dizer respeito a um cenário de recessão verificado nos Estados Unidos e na Europa, ao passo que regiões como a Ásia sofreram reduzidos impactos. Isso evidencia o caráter fabricado da acepção de crise global, que pode operar como “justificação moral e política" para intervenções internacionais de interesse de nações dominantes.

As três etnografias objetos de análise neste ensaio, realizadas em bolsas de valores nos anos de 1990, figuram como contribuições pioneiras, portanto, no processo de renascimento da antropologia econômica. Esse trio de estudos ajudará a engrossar uma série de reflexões subsequentes na disciplina sobre o capitalismo bradado como global que, a partir do olhar etnográfico clínico e crítico, acaba por revelar facetas heterogêneas, customizadas e inusitadas em realidades locais. Logo, se no passado, os campos da economia e da cultura haviam sido enquadrados intelectualmente como distintos - o primeiro voltado à racionalidade e o segundo conectado ao simbolismo - tais trabalhos antropológicos atestam definitivamente que ambos são, em verdade, inseparáveis. (Miyazaki, 2003; Appadurai, 2011; Riveros, 2013)

Importa ressaltar que, conforme avança a produção etnográfica em tal âmbito, naturalmente surgem divergências de condução analítica entre os autores. Nesse sentido, um estudo de destaque é o de Ho (2009), acerca da "cultura institucional" de Wall Street, representativo centro financeiro mundial. Em sua etnografia, ela identifica como parte de tal cultura a fabricação de crises acionárias corporativas, a fim de justificar reduções nos quadros funcionais de organizações estadunidenses. No esforço de situar tal reflexão, a antropóloga afirma desejar ir além de análises como a de Zaloom (2006) que, embora tenham contribuído para explicitar toda uma sociabilidade própria a "poderosos 
atores" do mundo financeiro, necessitam avançar de modo a evitar a "exotização" do mercado de capitais pela antropologia.

Ho (2009), por conseguinte, afirma preocupar-se em mapear discrepâncias, arbitrariedades e impactos "mundanos" nesse contexto, o que, de fato, não é o foco de Zaloom. Esta última interessa-se em evidenciar como pensam, trabalham e vivem operadores de mercado em Chicago e Londres no momento de consolidação de negociações eletrônicas em bolsas ao redor do planeta. A mesma linha segue Müller (2006), ao afirmar que, com sua etnografia na Bovespa, não objetivava efetuar a denúncia de contradições entre representações e práticas mercadológicas, posto inerentes a qualquer tipo de instituição. A antropóloga diz querer sim compreender "códigos de valores e de condutas" que subsidiam ações e cristalizam "realidades sociais".

Hertz (1998), por sua vez, também opta por direcionamento semelhante, quando afirma buscar responder não o que as ciências sociais têm a falar sobre os mercados financeiros, mas sim o que estes podem dizer sobre a sociedade. Entretanto, ao etnografar uma bolsa de valores nascida em um contexto político-econômico particular, que é o chinês, além de se dedicar a interpretá-lo segundo seus respectivos moldes, a antropóloga esforça-se por combater aquilo que Said (1990) denomina por "orientalismos". Estes constituem entendimentos estereotipados acerca do Oriente fabricados pelo Ocidente, em favor de supremacia própria.

Os caminhos etnográficos descritos aqui, portanto, a despeito de seus contrastes, desvelam uma pluralidade que tem se demonstrado profícua à construção do conhecimento e ao fortalecimento não só da antropologia econômica, mas da disciplina como um todo.

\section{Novos Olhares sobre a Economia da Dádiva}

As análises clássicas de B. Malinowski sobre o Kula e de F. Boas acerca do Potlatch ganharam um novo contorno a partir das reflexões de M. Mauss a respeito de tais rituais como representativos de uma "economia do dom". Esses estudos, tornados públicos entre final do século XIX e início do século XX, conferiram substrato à institucionalização da antropologia econômica, por revelarem que os intercâmbios de bens 
não visam a fins estritamente racionais, mas ocorrem principalmente a serviço de nutrir relações sociais. (Riveros, 2013)

Todavia, a forma como se deu a aplicação de tal arcabouço teórico concomitantemente impediu uma expansão mais ágil da referida subárea disciplinar. Duarte (2010) explica que, até a década de 1980, o pressuposto de reciprocidade presente na abordagem maussiana da dádiva esteve intrinsecamente associado às coletividades pré-industriais, consideradas a princípio os objetos de estudo por excelência da antropologia. Ou seja, acreditava-se que, nas sociedades industrializadas, existiam apenas resquícios desse mecanismo, já que nelas prevaleciam trocas comerciais impessoais.

Criou-se, dessa forma, o que Carrier (1995 apud Duarte, 2010), inspirado pela noção de "orientalismo" antes mencionada, chama de "ocidentalismo". Tal ideia quer criticar a polarização efetuada entre presentes e mercadorias, proporcional àquela entre coletividades primitivas e modernas, ambas oposições que determinaram percepções positivadas de sociabilidade para esse primeiro grupo e reservaram as negativadas ao segundo. Porém, ao contrário de Duarte, Appadurai (2011) afirma que o estabelecimento de tais dicotomias não pode ser atribuído a Mauss, mas sim ao emprego restrito e equívoco de sua teorização.

Mauss não figura como pensador antropológico clássico por acaso: para Appadurai (2011), ele detinha clareza acerca das afinidades existentes entre as modalidades de troca pré e pós-industriais, evidenciada pelas comparações cosmológicas que efetua ao longo de sua análise. Porém, a antropologia econômica, em reflexo a uma postura da disciplina como um todo, procrastinou em transcender essa divisão, cujo esforço de superação tem rendido notáveis avanços ${ }^{3}$. As etnografias que estão no centro da presente análise são reveladoras dessa empreitada: as três voltam-se a Mauss para pensar as relações estabelecidas entre os atores que movimentam o dia a dia das bolsas.

Tanto Müller (2006) quanto Zaloon (2006) ressaltam que as relações de reciprocidade nas Bolsas de São Paulo e Chicago não se configuram elementos paralelos e sim constitutivos das negociações. A mutualidade historicamente permeia uma ampla e funcional rede 
de relacionamentos entre atores diversificados: representantes das empresas de capital aberto; proprietários, sócios e empregados das organizações autorizadas a operar nas bolsas; profissionais autônomos; investidores corporativos e individuais; analistas de mercado e jornalistas. Reconhecer esse circuito etnograficamente possibilita desmistificar lugares-comuns acerca das bolsas de valores, percebidas ora como ambientes perpassados pelo caos, ora como espaços ultrarracionalizados.

A referida rede configura um arranjo duradouro e normatizado, operacionalizado no cotidiano mercadológico e fora dele, com repercussões diretas sobre os negócios, a carreira e a identidade de indivíduos que, em grande parte, não só investem na bolsa em representação de outrem, mas são eles mesmos especuladores, em prol de patrimônio próprio. Os intercâmbios de dádivas nesse âmbito são interessados - ou seja, não se dão por simpatia ou camaradagem -, firmemente pautados na lógica de dar, receber e retribuir. Não conferir completude a tal ciclo significa arriscar dinheiro e reputação.

Desse modo, a depender do contexto factual, hierárquico e até mesmo parental, as trocas incluem desde técnicas, gentilezas, indicações, privilégios e prêmios profissionais a presentes, viagens, festas, bebidas, drogas e mulheres. Mas todos esses intercâmbios, em realidade, são meios para se trocar informações, o bem mais precioso em um mercado futuro de risco. Tais relações são praticadas e não escritas, pois nem sempre ocorrem em consonância com formalidades institucionais e, muitas vezes, as corrompem. A medida do desafio às regras é a manutenção da credibilidade pública das bolsas, determinante para a confiança dos investidores e da sociedade.

A substituição do pregão à viva voz pelo eletrônico transforma, mas não desmorona essa complexa rede de relacionamentos. Zaloom (2006) demonstra que a resistência de segmentos da Bolsa Chicago à digitalização referia-se justamente à preocupação em manter a vitalidade desse modelo erigido e favorecido por relações face a face. Contudo, o mercado eletrônico, embora uma mudança tecnológica de magnitude, não era a primeira vivenciada pela instituição, cujo fortalecimento nacional e internacional se deu em compasso com a 
construção de infraestrutura de escoamento de produtos regionais; com a evolução arquitetônica dos espaços de negociação; com a introdução dos telégrafos, dos telefones com e sem fio, dos painéis de néon e dos computadores.

A bolsa e seu conjunto relacional haviam, portanto, sobrevivido e se adaptado a todas essas modificações também impactantes. Sob tal olhar, as negociações eletrônicas, ao dispensar uma série de intermediários, compactaram as redes pessoais de outrora, assim como as virtualizaram, demandando outras ferramentas para ler o mercado que não o corpo a corpo do pregão à viva voz. O que se altera, entretanto, é mais a forma do arranjo: o conteúdo de reciprocidade permanece, visto que a ambiguidade dos números do mercado não se extingue, a despeito da busca incessante pela transparência institucional que rege, em tese, as bolsas de valores.

Ainda que à primeira vista pareçam neutras nos monitores digitais, as cotações continuam a ser objeto de interpretação e manejo por parte dos operadores. Assim, no mercado eletrônico, distribuídos em espaços compartimentados de negociação, eles continuam a trocar informações, bem como combinam escusos movimentos de mercado com colegas de sala ou com outros profissionais, via telefone e internet. Ademais, os intercâmbios informacionais continuam a fluir nos ambientes extramercadológicos, como nas embriagantes celebrações apreciadas por esses profissionais.

Se nas bolsas ocidentais, embora alastrado, o exercício da dádiva se mostra cercado por certo ocultamento, na China ocorre o contrário. Nesse país, a inserção do dom não é apenas difusa, mas consciente e valorizada para a realização de bons negócios. Por conseguinte, nada mais natural que tenha impactado as operações da nascente Bolsa de Shanghai etnografada por Hertz (1998). A prática da reciprocidade entre os chineses, denominada guanxi, cristaliza uma verdadeira instituição social. De origens imperiais, o guanxi experimenta um reflorescimento no contexto pós-Mao, movimento que repercute um ethos chinês articulado à abertura econômica nacional, sendo determinante à trajetória particular da nação asiática no universo capitalista contemporâneo. 
Efetuar guanxi significa estabelecer vínculos pessoais selecionados, que pressupõem uma gama de obrigações - dentre elas, lealdade, intercâmbio de informações e ajuda mútua - e permitem assim relacionamentos entre indivíduos hierarquicamente diversos. Trata-se de um mecanismo primordial para o estabelecimento de negociações na China, das mais simples às complexas, entendido como criador de uma atmosfera de fluidez e segurança. A materialização do guanxi ocorre no decorrer de um tempo especificamente relacional, por intermédio de uma série de ritos, como a promoção de jantares, o ato de brindar, a troca de presentes ou a concessão de privilégios políticos. Aos olhos chineses, guanxi definitivamente não constitui suborno, posto que este último resulta de articulações pontuais não afetivas. (Pinheiro -Machado, 2011)

$\mathrm{Na}$ "febre de ações" verificada quando do surgimento da Bolsa de Shanghai, Hertz (1998) relata que os candidatos a investidores poderiam passar horas, até mesmo dias, em filas defronte aos escritórios de corretagem. Muitas vezes, a depender da intensidade do movimento, eles não tinham muito poder de escolha na hora da compra, lançando mão de um "sistema lotérico" de ações. Além disso, não havia muita informação disponível para direcionar os negócios. Diante desse quadro, os investidores, especialmente os de maior poder financeiro, acionaram suas conexões guanxi para se inserir e operar na bolsa mais facilmente. Isso incluía obter notícias antecipadas sobre interferências regulatórias estatais, selecionar ações desejáveis e mesmo se ausentar do trabalho sem decorrências para realizar operações.

Sem dúvida, as aplicações aqui expostas de uma economia da dádiva no mercado financeiro são apenas algumas possibilidades diante de um arcabouço teórico de amplo alcance. Appadurai (2011), por exemplo, explora uma outra de igual modo interessante: visualizar como homólogos aos potlatchs os movimentos de alto risco dos especuladores contemporâneos. A exemplo dos indígenas norte-americanos quando ateavam fogo aos seus bens a fim de reverberar prosperidade, esses investidores assumem "desafios elevados para retornos elevados", numa busca incessante por "crédito e honra". 


\section{Gradações em Torno da Economia Global}

A temática da globalização passou, até os anos de 1980, a ser parte das preocupações centrais da antropologia. Segundo O. Velho (1997), tal quadro encontra explicação no alicerce científico no qual se constituiu a disciplina, assentado na busca de compreensão das singularidades culturais. Ou seja, em tese, um campo do conhecimento estabelecido na contracorrente globalizante de cunho homogeneizador. Não obstante, movimentos culturais inusitados, de caráter concomitantemente local e global, exigiram repensar os fundamentos etnográficos tradicionais. É baseado nisso que Velho propõe abandonar concepções clichês de globalização - como profecia, modismo ou fenômeno ocidentalizante -, em prol de uma abordagem antropológica que a enxergue como um "mito" da contemporaneidade.

Nesse sentido, a globalização coloca-se como um instrumento lógico-cultural para pensar as contradições do real. Trata-se de um mito com várias versões e é todas elas - como qualquer narrativa dessa espécie -, inclusive aquelas contrárias à globalização. E, também como todo mito, a globalização possui seus ritos associados, os quais retrabalham no plano prático os conflitos pensados pelas narrativas no nível especulativo. Os pregões das bolsas de valores ao redor do mundo são parte, como também assinala Müller (2006), desse conjunto de rituais paradigmáticos. Parecida mas diferente em cada lugar, a dinâmica das bolsas contribui para a pluralidade de versões do mito global.

Tais constatações conduzem a pensar, nos termos de Comaroff e Comaroff (2001), acerca do "engajamento contraditório e ambivalente" dos estados nacionais no âmbito do capitalismo neoliberalista de pretensões globais. Muito se alardeou acerca da obsolescência do Estado-nação diante da globalização, cujos fluxos produtivos, informacionais, culturais e de capital transcenderiam por completo fronteiras territoriais. Na prática, entretanto, se a nação aparta-se do Estado em determinados contextos, isso não se mostra possível na totalidade deles, tendo em vista que os referidos fluxos funcionam por intermédio de sujeitos e organizações em alguma medida territorializados. Assim, a economia se movimenta global, mas não livremente 
e o agente convocado a regulá-la é o Estado, que o faz a partir de uma perspectiva nacional.

As "especificidades culturais", dessa maneira, não freiam a "monetarização" global, mas operam como "contrapeso" (Oliven, 2001). $\mathrm{Na}$ época em que realizou etnografia na Bovespa, embora o pregão à viva voz predominasse, Müller (2006) conta que já havia um sistema eletrônico em experimentação, de origem canadense, chamado CATS. Mas não foi possível explorá-lo no Brasil da forma literalmente pensada por seus idealizadores. Contou à antropóloga um informante no cargo de gerente operacional:

Quando a bolsa comprou o sistema CATS, a gente conversou com o pessoal de Toronto sobre as modificações do sistema que a gente precisava. A gente pediu, por exemplo, um 'sisteminha' de leilão. E os caras perguntaram: 'Mas pra que leilão?' Não se conformavam. Porque a cultura deles é aquela... o papel oscila e tudo bem. Aqui não. [...] É impressionante. Quando a gente começou com o CATS os caras falaram assim: - Pro cara fazer uma 'mutreta' no CATS vai ser fogo. Mas os caras já estavam achando uma nova forma de... [direcionar coletivamente o movimento das cotações e consequentemente dos negócios] Então, em função disso, dos brasileiros, é que precisa ter um controle. (Müller, 2006, p. 33-34)

O casal Comaroff (2001) aponta que uma das mais evidentes metamorfoses experimentadas pelos estados nacionais, em meio ao capitalismo global, reside na proliferação de políticas públicas multiculturais. Dessa forma, ao abrir mão de uma homogeneização populacional idealizada, o Estado procura aproximar-se da nação conferindo valor à alteridade. Zaloom (2006) pôde constatar as repercussões disso no mercado, no período em que atuou como trainee na filial londrina da corretora a que se vinculou em Chicago.

Conforme mencionado, a abertura de tal escritório em Londres configurou um experimento. A ideia dos patrões de Zaloom era preparar-se para o definitivo ingresso do pregão eletrônico na Bolsa de Chicago, a partir da vivência no já digitalizado mercado inglês. Tal escolha não se deu ao acaso: no passado, os britânicos é que haviam 
se inspirado no modelo altamente especulativo de negócios futuros em Chicago. Influências mútuas, desse modo, apontavam para a obtenção de um empreendimento piloto exitoso.

Como dito, o jeito típico de negociar na Bolsa de Chicago incluía, além da experiência em produtos derivativos, acordos prioritariamente baseados em redes pessoalizadas, movimentadas por homens brancos, de diferentes níveis educacionais, portadores de uma ampla história institucional. Os cabeças do experimento na Inglaterra aproveitaram a saída dos Estados Unidos para subverter essa ordem. Eles lançaram mão de diretrizes multiculturalistas em voga no período, mas ainda longe de alcançar o conservador mercado de Chicago, para colocar à prova um grupo diferenciado de trainees.

Houve o recrutamento de indivíduos jovens, homens e mulheres, graduados, sem conexões pessoais entre si, familiarizados tecnologicamente, de diferentes origens étnicas e, em tese, ávidos por enriquecer. Esperava-se que esse conjunto profissional culturalmente diverso, devidamente preparado com o melhor do modus operandi das bolsas de Chicago e Londres, poderia contribuir para a liquidez dos negócios. Como assinala Zaloom (2006), a "engenharia social" ia assim ao encontro da "máquina financeira".

A etnografia de Hertz (1998), por fim, revela-se emblemática no contexto em análise, porque descreve, propriamente, o esforço de um Estado-nação em modelar um mercado acionário que satisfaça suas características distintivas. Desse modo, na Bolsa de Shanghai, o Estado configura um player tão fundamental quanto os demais investidores. Nos primeiros passos operacionais dessa instituição, as ações disponíveis pertenciam a empresas completa ou parcialmente públicas. O Estado também detinha a propriedade das corretoras. O mercado estrangeiro estruturou-se separadamente do doméstico: enquanto este primeiro era apresentado à comunidade internacional como emergente, o segundo foi objeto de sucessivas tentativas de controle de movimentações.

A "febre acionária", por sua vez, ao colocar em xeque a regulação estatal, não delineou, de modo algum, uma mobilização social de feições democráticas. Segundo Hertz (id.), trata-se sim de um movimento "contra-hegemônico" num contexto de dominância estatal, em meio a 
reformas de tom capitalista. A ânsia por ações deve ser assim situada num cenário de uma série de febres experimentadas pela China urbana, as quais determinam a adesão de enormes contingentes populacionais a modas diversificadas.

Nas febres, ao mesmo tempo em que se lançam a uma atuação massiva intrinsecamente conectada com a história política do país, os chineses buscam diferenciar-se nos limites da coletividade. Tais fenômenos espelham uma atmosfera conflitante entre indivíduos e uma sociedade em transformação. Refletem não um capitalismo global, mas um paradoxal "capitalismo chinês" (Pinheiro-Machado, 2011).

\section{Interlocuções com a Antropologia da Religião}

Ao defender uma abordagem antropológica da globalização, O. Velho (1997; 1998) ressalta a importância de, nesse processo, conferir atenção não apenas à alteridade, objeto clássico de atenção da disciplina, mas também às "semelhanças e aproximações contingentes". Não determinadas de antemão, essas similitudes se elaborariam pela "abertura de narrativas" no cenário globalizante a partir de "dentro" dos grupos culturais.

Segundo ele, em tal contexto, o caso da religião mostra-se exemplar. O autor identifica o avanço de uma "pentecostalização" em meio a toda a esfera religiosa brasileira. Esse termo aponta para uma circunvizinhança teológica entre crenças historicamente conflitantes - como a evangélica neopentecostal, a carismática católica ou a new age -, que reside no princípio de que a prosperidade humana, em todos os níveis, é legítima, abençoada e libertadora.

Tadvald (2012) constata que, contemporaneamente, a referida "pentecostalização" vem experimentando um processo de exportação capitaneado pela Igreja Universal do Reino de Deus. Comaroff e Comaroff (2001) avançam nessa análise e percebem que não se trata de um movimento exclusivamente religioso, mas integrante do que eles denominam por "capitalismo messiânico", no âmbito do qual a atuação de instituições como a Igreja Universal pode ser inusitadamente aproximada do fenômeno de explosão dos mercados financeiros mundiais. 
Nesse panorama, o receituário capitalista técnico, racional e progressista emerge como um "evangelho de salvação", cuja estrita observância conduziria ao êxito pessoal, inclusive de marginalizados social e economicamente. Tornar-se adepto da Igreja Universal ou investidor na bolsa de valores constituem assim tentativas correspondentes de manejo de um capital que pode florescer "a partir do nada", independentemente de esforços presentes ou histórias pregressas, como se o planeta fosse um "cassino".

Se no templo um deus é a entidade mística a mediar esse processo, na bolsa o mercado ocupa essa posição. Este último registra na atualidade um ritmo exponencial de trocas virtuais, completamente dissociadas do plano da produção material, que carecem de clareza imediata, geram cifras astronômicas e, portanto, adquirem uma aura de mistério e de ocultismo, própria do domínio religioso. Appadurai (2011) resume tal lógica capitalista - que desestrutura a tradicional de caráter weberiano - numa máxima explorada hoje publicamente por dirigentes políticos, pela mídia, entre outros atores: "a fé no mercado".

As etnografias em análise neste ensaio ofertam claros indícios desse estado de coisas. Na Bolsa de Chicago, Zaloom (2006) verificou o emprego de uma linguagem divinatória entre os operadores para se referir ao funcionamento mercadológico. Eles aludem ao mercado como uma entidade de vida própria, que atua como juiz absoluto entre os negociadores. O sucesso ou o fracasso financeiro estão, desse modo, conectados ao cumprimento ou não da disciplina do mercado. Esta pressupõe que, no momento das negociações, os operadores desliguemse do mundo externo, desumanizem-se, para atingir uma condição descrita quase como um transe, que lhes permite administrar riscos e investimentos como "máquinas financeiras".

Essa narrativa, a um só tempo racionalizada e mística, deixa em suspenso as redes pessoais, os acordos mercadológicos, a pura especulação, a criação de crises, enfim, tudo aquilo que, de fato, movimenta os negócios, mas pode colocar em xeque a credibilidade deles. Um momento representativo para observar todo esse conteúdo em ação, segundo Müller (2006), é o de "bolha especulativa", que abrange o aumento contínuo dos preços das cotações, em decorrência de uma 
excessiva confiança de liquidez entre os operadores. As compras de ações e derivativos nesses períodos encadeiam-se de forma mais emocional que fundamentada, no compasso de uma comoção coletiva.

Nesse quadro, entra em cena o mercado como entidade autônoma que, ao estourar a bolha, relembra aos negociadores sua idealizada ética disciplinar, de atuação individual e racionalizada. Alguns deles fracassam financeiramente a ponto de cair no ostracismo profissional e chegar até mesmo ao suicídio. Outros, considerados sortudos, saem exitosos e podem explicar seu sucesso a partir da adesão anterior a "práticas ritualizadas", típicas do "pensamento mágico", como carregar sal grosso no bolso ou cuidar para não vestir uma meia do avesso.

Hertz (1998) também identificou "concepções mítico-religiosas" conectadas à "febre de ações" que permeou o nascimento da Bolsa de Shanghai, mas logicamente estas se alicerçam na cultura chinesa. Conforme explicitado, o apetite acionário dos chineses fez parte de um contexto de adesão a modas urbanas que se sucediam no país. Dentre elas, esteve a dispersão pela cidade, no início dos anos de 1990, de pequenos retratos de Mao Tsé-Tung, ícone da Revolução Cultural Chinesa. Quando questionados sobre os motivos dessa febre, os chineses ofertavam várias respostas: diziam desde o óbvio, que a imagem de Mao era um símbolo fashion, até que portava boa sorte e que, para muitos, situava-se como divina.

Tal endeusamento se deve à existência de narrativas acerca de acontecimentos catastróficos ou miraculosos atribuídos a comportamentos populares desafiadores ou veneradores da figura desse chefe político, durante ou após sua soberania, que se estendeu até meados dos anos de 1970. Hertz explica que histórias nesses moldes estão em circulação no país desde pelo menos o século XII. Quase sempre, as narrativas centram-se nas proezas de algum herói, que determina o surgimento de cultos localizados, os quais atraem peregrinações e acabam por se espalhar nacionalmente.

Contemporaneamente, a febre em torno da figura de Mao foi intensificada pela associação dela à sobrevivência de uma série de vítimas de acidentes de carro. Coincidência ou não, o retrato da liderança política de outrora era bastante estampado em táxis. O que chama a 
atenção nesses episódios, segundo Hertz (1998), é o fato de sediarem-se em centros urbanos importantes para a reforma econômica da China pós-Mao, dentre eles, Shanghai.

Para a antropóloga, as histórias acerca dos feitos milagrosos vinculados a Mao operam como instrumentos reflexivos acerca de inquietações populares diante das mudanças em desenvolvimento no país. Dessa forma, tanto as narrativas quanto as febres desencadeadas em torno de tais transições, das quais a criação da bolsa é representativa, ecoam a tensão indivíduo/sociedade na China atual, como já problematizado aqui.

\section{Interfaces com a Antropologia das Emoções}

Desde a constituição da antropologia como disciplina, as emoções, como elementos importantes de sociabilidade, aparecem abordadas com recorrência nas etnografias, embora não em primeiro plano. Segundo Rezende e Coelho (2010), somente a partir dos anos de 1990, os sentimentos começam a se tornar objeto central de monografias, sob uma ótica "contextualista", que aspira a analisar a expressão deles no âmbito de "relações sociais e de poder" nos mais diversos cenários situacionais.

Além de mapear o estado da arte da antropologia das emoções como subárea disciplinar, essas duas estudiosas têm se dedicado a identificar os traços distintivos da emotividade ocidental moderna. Apoiadas nas reflexões de pensadores como N. Elias, Z. Bauman, R. Sennett e P. Bruckner, elas postulam que os sujeitos modernos exercem um profundo autocontrole sobre as emoções, decorrente de macrofenômenos experimentados pela sociedade ocidental, como a rígida separação entre as esferas privada e pública, a busca incessante por civilidade, o individualismo e a internalização psíquica dos sentimentos.

Como repercussões desse arranjo, têm-se, de um lado, o estabelecimento de uma visão condenatória da perda de domínio emocional e, de outro, um enorme avanço de práticas de caráter narcisista e hedonista, numa contracorrente perante o excessivo controle da subjetividade. Em tal panorama, é possível estabelecer novas "semelhanças e aproximações contingentes" (Velho, 1997), por exemplo, 
entre a explosão do consumo, dos esportes radicais, das opções de entretenimento midiático, de mecanismos de rejuvenescimento, da variedade e do uso de drogas.

Baseada no pensamento dumontiano, Müller (2006) argumenta que o entendimento da economia como setor autônomo em relação à sociedade e o surgimento do mercado financeiro situam-se, simultaneamente, como causa e efeito da sociedade moderna capitalista, bem como do conjunto de práticas emotivas a ela associada. Desse modo, refletir sobre a elaboração da subjetividade e da identidade dos operadores das bolsas de valores revela-se de grande valia para aprofundar o entendimento desse panorama, algo que Müller (2006) e Zaloom (2006) procuram fazer em suas etnografias.

Tanto no mercado acionário de São Paulo como de Chicago, os diacríticos da emotividade ocidental surgem exacerbados, justamente por tais espaços cristalizarem a concepção de uma esfera econômica apartada da sociedade, na qual atua uma comunidade fechada, altamente especializada. Dessa forma, o ideal moderno de controle emocional individual é explorado às últimas consequências, pois teoricamente permite o manejo do risco e a obtenção do sucesso, seja para os clientes, seja para os operadores que, como dito, em sua esmagadora maioria investem também para si próprios, ainda que na surdina.

Nesse sentido, embora sustentada por extensas redes de relações, a carreira desses indivíduos é por eles visualizada como um empreendimento estritamente pessoal, no qual a ascensão pode ser muito rápida, porém, cerceada pelo fracasso, de ordem financeira, fisiológica ou social, dado o frenético ritmo laboral, que restringe a sociabilidade familiar. Trata-se, nos termos de G. Velho (2013), de um "projeto" profissional de "negociação da realidade" e de "antecipação no futuro", que inclui, obrigatória mas não abertamente, a relação com o outro. Esse "projeto", associado a uma "biografia" e a uma "trajetória", comunica "interesses, objetivos, sentimentos e aspirações" desses sujeitos numa cultura individualista.

Em virtude disso tudo, afirmam Müller (2006) e Zaloom (2006), a metáfora do mercado como um jogo, a ideia do investidor como puro especulador ou o perfil do operador inconsequente, "viciado" no mercado, são publicamente condenadas, dado que colocam em 
risco a legitimidade identitária do "homem de negócios", vinculada à credibilidade institucional das bolsas. Contudo, tais acepções existem porque, como relatam os operadores mesmos, o exercício mercadológico ocorre, paradoxalmente, impulsionado pelo instinto e pelo prazer de investir, inteiramente conectado ao tamanho do risco abraçado.

O cotidiano das negociações, na contramão do controle emocional, é descrito como uma guerra de cada um por si, na qual indivíduos em competição destilam insultos, não raro de conteúdo viril e sexual, bem como se denominam por termos animalescos ${ }^{4}$. Nesse contexto, o deleite mercadológico não resulta apenas do êxito financeiro, mas também daquilo que ele pode proporcionar na vida fora das negociações. Dessa maneira, o dia a dia dos operadores fora do pregão é publicamente marcado pelo consumo de roupas de grife, relógios, carros, bebidas, drogas, pornografia, dentre outros signos de opulência. O acesso contínuo a esses bens significa manutenção do prestígio na rede de relacionamentos que movimenta o mercado, haja vista sinalizarem a magnitude do investidor.

Por conseguinte, as contradições extremadas intrínsecas à construção da identidade dos operadores das bolsas de valores possibilitam perceber quão árdua é a elaboração da subjetividade ocidental, posto que lida todo o tempo com elementos grandemente conflitantes, ora de domínio sentimental, ora de total fruição. No caso dos participantes do mercado, para usar termos de Zaloom (2006), ser bem-sucedido nesse processo significa alcançar a "liquidez do ego"; o contrário, por seu turno, abre espaço a um verdadeiro "colapso do self".

Na Bolsa de Shanghai, Hertz (1998) identifica rebatimentos desse quadro quando traça o perfil dos chamados "grandes jogadores" (dahu) do então nascente mercado acionário chinês. Trata-se de um "tipo ideal", presente no imaginário dos investidores de pequena escala (sanhu), percebido como uma espécie de "cowboy", simultaneamente admirado e repudiado: alguém detentor de certo capital inicial, de origens nebulosas (inclusive ilegais), cuja aplicação bem-sucedida no mercado financeiro aparecia conectada ao pleno exercício da individualidade, portanto, desassociada do apoio das duas principais entidades sociais chinesas, o Estado e a família. 
Segundo a autora, em termos maussianos, um dahu estaria idealmente livre da obrigação de dar, receber e retribuir. A esse tipo de indivíduo estariam vinculados elementos tais como a liberdade, a virilidade, a excitação, o poder de consumo e a licenciosidade sexual, frutos da especulação bem-sucedida. Todavia, Hertz alerta para a necessidade de enxergar essa figura quimérica não sob uma ótica capitalista, baseada na admiração da massa pela prosperidade de um grupo de investidores, mas sim com base numa lógica chinesa. De acordo com esta última, um grande investidor continuaria a ser considerado um dahu mesmo que perdesse toda a sua riqueza, posto o fracasso decorrer de sua intrínseca liberdade de ação.

Logo, o misto de fascínio e desdém popular em torno desses especuladores diz mais respeito ao fato de atuarem como "espelho contra-hegemônico" do controle estatal da economia. Indivíduos dahu não adotavam deliberadamente tal postura, mas a ocasionavam pela capacidade de injetar no mercado fluxos maiores de capital, responsáveis por gerar uma volatilidade ora promissora, ora comprometedora para a atuação dos pequenos investidores, mas sempre indesejada do ponto de vista oficial. Novamente aqui percebe-se um contingente de indivíduos no processo de criar narrativas que deem conta de novas formas de agência em torno da inserção da China no panorama econômico global.

\section{Considerações Finais}

As discussões empreendidas neste ensaio coadunam-se com a premissa de Riveros (2013) de que a antropologia tem a prerrogativa e o dever de analisar criticamente a economia contemporânea de modo a frear a propagação de um "neoliberalismo irreflexivo". Nesse sentido, os empreendimentos etnográficos - como os realizados em bolsas de valores, aqui expostos - têm demonstrado grande potencial de evidenciar características operacionais do chamado capitalismo global não perceptíveis a olhares apressados.

Dentre elas, segundo o casal Comaroff (2001), destacam-se: a capacidade de incluir e, ao mesmo tempo, marginalizar socioecono- 
micamente de modos cada vez mais inesperados; de gerar "desejos e expectativas" de consumo em âmbito global, enquanto reduz a segurança laboral e individual; de ampliar as diferenças entre classes e, concomitantemente, solapar a consciência acerca delas; de fazer prosperar aqueles que dominam "tecnologias espectrais" do sistema financeiro e colocar em risco a existência dos que ficam à parte.

Nesse panorama, a etnografia revela não apenas as contradições e os conflitos em escala planetária, mas também as especificidades e as "dialéticas" locais que se desencadeiam. Visualizar tais singularidades permite desenhar conclusões mais amplas sobre tal intrincado processo, posto não homogêneo. Dessa maneira, por meio da observação analítica e comparativa de diferentes contextos - São Paulo, Chicago, Londres e Shanghai - constata-se que os responsáveis por movimentar instituições financeiras globais como as bolsas de valores, ao deterem técnicas, relacionamentos, tecnologias e, especialmente, aval social que lhes propiciam impulsionar um volume de trocas virtualizadas sem precedentes, atuam de maneira cada vez menos restringida pela "economia moral do trabalho concreto". (Comaroff, 2001)

Do ponto de vista da justiça social, o cenário é desalentador. Não obstante, Miyazaki (2003), ancorado nas possibilidades de repercussão do esforço teórico-etnográfico, fala em uma "antropologia da esperança" que, inspirada na capacidade do mercado financeiro em prospectar acerca do porvir, fomentaria não formas alternativas ao capitalismo, mas caminhos para "reimaginar o futuro". A proposta soa ousada. Ela carrega um conteúdo afetivo que, como apontam autores como O. Velho (1997) e Favret-Saada (2005), a antropologia vem cada vez mais se encorajando a abraçar, ao longo da empreitada de se desfazer das amarras de um racionalismo historicamente exigido para fortalecê-la cientificamente.

A despeito de maiores ou menores afinidades com proposições como a de Miyazaki (2003), os antropólogos dedicados a pensar direta ou indiretamente a economia concordam num ponto: a necessidade de compreensão acertada e de intervenção assertiva no complexo e controverso quadro financeiro contemporâneo faz a disciplina pulsar mais que nunca, para usar uma expressão de Peirano (1992), "a favor da etnografia". 
Agradeço a Ruben G. Oliven pelas valiosas interlocuções para a elaboração deste ensaio no âmbito do Seminário de Doutorado do Programa de Pós-Graduação em Antropologia Social (PPGAS) da UFRGS.

\section{Notas}

1 A BOVESPA transformou-se, no ano de 2008, em BMEFBOVESPA, a partir da fusão com a também brasileira Bolsa de Mercadorias \& Futuros.

2 Os produtos do mercado de derivativos são aqueles que têm preço derivado de outras commodities, dentre elas ações empresariais e mercadorias físicas, como safras agrícolas, por exemplo, largamente negociadas na Bolsa de Chicago. Os derivativos exploram as tendências futuras das cotações dos itens a eles vinculados e servem, desse modo, a dois propósitos: ao manejo do risco, como uma espécie de seguro e, simultânea e paradoxalmente, à especulação.

3 Nesse sentido, por exemplo, cf. em Goldman e Lima (1999).

4 Aqui impossível não recordar o título de uma recente produção cinematográfica do diretor norte-americano Martin Scorsese, intitulada O Lobo de Wall Street. Ambientado nos anos de 1990, o filme conta a trajetória real do especulador Jordan Belfort, cujo enriquecimento rápido e fraudulento the rendeu no mercado financeiro o apelido de "Lobo". Interessantemente, Belfort também era chamado de Gordon Gekko, grande investidor inescrupuloso, personagem fictício de Wall Street, uma película de 1987, dirigida por Oliver Stone (cf. epígrafe).

\section{Referências}

APPADURAI, Arjun. The ghost in the financial machine. Public Culture, Durham, v. 23, n. 3, p. 517-539, 2011.

COMAROFF, Jean; COMAROFF, John L. Millennial capitalism: first thoughts on a second coming. In: COMAROFF, Jean; COMAROFF, John L. (Org.). Millennial capitalism and the culture of neoliberalism. Durham; London: Duke University Press, 2001. p. 1-56.

DUARTE, Alice. A antropologia e o estudo do consumo: revisão crítica das suas relações e possibilidades. Etnográfica, Lisboa, v. 14, n. 2, p. 363-393, jul. 2010.

FAVRET-SAADA, Jeanne. Ser afetado. Tradução de SIQUEIRA, Paula. Cadernos de Campo, São Paulo, n. 13, p. 155-161, 2005.

GOLDMAN, Marcio; LIMA, Tânia Stolze. Como se faz um Grande Divisor? In: GOLDMAN, Marcio (Org.). Alguma antropologia. Rio de Janeiro: Relume Dumará, 1999. p. 83-92.

HERTZ, Ellen. The trading crowd: an ethnography of the Shanghai Stock Market. Cambridge: Cambridge University Press, 1998. 
HO, Karen. Disciplining investment bankers, disciplining the economy: Wall Street's institutional culture of crisis and the downsizing of "Corporate America". American Anthropologist, [on-line], v. 111, n. 2, p. 177-189, 2009.

MIYAZAKI, Hirokazu. Economy of dreams: the production of hope in anthropology and finance. CSES Working Paper Series, Ithaca, n. 15, 49 p., nov. 2003.

MÜLLER, Lúcia Helena Alves. Mercado exemplar: um estudo antropológico sobre a bolsa de valores. Porto Alegre: Zouk, 2006.

O LOBO DE WALL STREET. Martin Scorsese. Estados Unidos, 2013. 179 $\min$, cor.

OLIVEN, Ruben George. De olho no dinheiro nos Estados Unidos. Estudos Históricos, Rio de Janeiro, n. 27, p. 206-235, 2001.

ORTIZ, Horacio. The limits of financial imagination: free investors, efficient markets, and crisis. American Anthropologist, [on-line], v. 116, n. 1, p. 38-50, 2014.

PEIRANO, Mariza. A favor da etnografia. Série Antropologia, Brasília, DF, n. 130, 21 p., 1992.

PEIRANO, Mariza. Etnografia não é método. Conferência proferida nas comemorações dos 40 Anos de Pós-Graduação em Antropologia Social da UFRGS, 12 mar. 2014. Disponível em: <www.marizapeirano.com.br>. Acesso em: $1^{\circ}$ jul. 2014.

PINHEIRO-MACHADO, Rosana. Fazendo guanxi: dádivas, etiquetas e emoções na economia da China pós-Mao. Mana, Rio de Janeiro, v. 17, n.1, p. 99-130, 2011.

REZENDE, Claudia Barcellos; COELHO, Maria Claudia. Antropologia das emoções. Rio de Janeiro: Editora FGV, 2010.

RIVEROS, Mauricio Montenegro. Entre las crisis globales y los contextos locales: elementos para una introducción a la antropología económica. Antípoda, Bogotá, n. 17, p. 109-131, jul./dic. 2013.

SAID, Eduard W. Orientalismo: o Oriente como invenção do Ocidente. São Paulo: Companhia das Letras, 1990.

TADVALD, Marcelo. Guerra santa de exportação: rituais iurdianos na Argentina e o diálogo com o contexto receptor. In: $28^{\mathrm{a}}$ REUNIÃO BRASILEIRA DE ANTROPOLOGIA, 2012, São Paulo. Anais... Brasília, DF: Associação Brasileira de Antropologia, 2012.

VELHO, Gilberto. Um antropólogo na cidade: ensaios de antropologia urbana. Rio de Janeiro: Zahar, 2013. 
VELHO, Otávio. Globalização: antropologia e religião. Mana, Rio de Janeiro, v. 3, n.1, p. 133-154, 1997.

VELHO, Otávio. A antropologia da religião em tempos de globalização.

Etnográfica, Lisboa, v. 2, n. 2, p. 347-357, 1998.

VELHO, Otávio. A religião é um modo de conhecimento? Plura, [on-line], v. 1, n, 1, p. 3-37, 2010.

ZALOOM, Caitlin. Out of the pits: traders and technology from Chicago to London. Chicago: The University of Chicago Press, 2006.

WALL STREET PODER E COBIÇA. Oliver Stone. Estados Unidos, 1987. $125 \mathrm{~min}$, cor.

WALL STREET O DINHEIRO NUNCA DORME. Oliver Stone. Estados Unidos, 2010. $127 \mathrm{~min}$, cor.

Recebido em 27/10/14

Aceito em 11/12/2014 